J. Dairy Sci. 99:4309-4324

http://dx.doi.org/10.3168/jds.2015-9603

(C) American Dairy Science Association ${ }^{\circledR}, 2016$.

\title{
Exposure of fluid milk to LED light negatively affects consumer perception and alters underlying sensory properties
}

\author{
Nicole Martin, ${ }^{*}$ Nancy Carey, ${ }^{*}$ Steven Murphy, ${ }^{*}$ David Kent, ${ }^{*}$ Jae Bang, ${ }^{*}$ Tim Stubbs, $†$ Martin Wiedmann, ${ }^{*}$ \\ and Robin Dando*1 \\ *Department of Food Science, Cornell University, Ithaca, NY 14853 \\ †Dairy Management Inc., Rosemont, IL 60018
}

\begin{abstract}
Fluid milk consumption per capita in the United States has been steadily declining since the 1940s. Many factors have contributed to this decline, including the increasing consumption of carbonated beverages and bottled water. To meet the challenge of stemming the decline in consumption of fluid milk, the dairy industry must take a systematic approach to identifying and correcting for factors that negatively affect consumers' perception of fluid milk quality. To that end, samples of fluid milk were evaluated to identify factors, with a particular focus on light-emitting diode (LED) light exposure, which negatively affect the perceived sensory quality of milk, and to quantify their relative effect on the consumer's experience. Fluid milk samples were sourced from 3 processing facilities with varying microbial postprocessing contamination patterns based on historical testing. The effect of fat content, light exposure, age, and microbiological content were assayed across 23 samples of fluid milk, via consumer, descriptive sensory, and instrumental analyses. Most notably, light exposure resulted in a broad negative reaction from consumers, more so than samples with microbiological contamination exceeding $20,000 \mathrm{cfu} / \mathrm{mL}$ on days approaching code. The predominant implication of the study is that a component of paramount importance in ensuring the success of the dairy industry would be to protect fluid milk from all sources of light exposure, from processing plant to consumer.
\end{abstract}

Key words: fluid milk, sensory, consumer, hedonic, light

\section{INTRODUCTION}

Fluid milk is one of the most important dairy commodities produced in the United States. Per capita

Received March 20, 2015.

Accepted February 20, 2016.

${ }^{1}$ Corresponding author: robin.dando@cornell.edu consumption in the United States has fallen, however, by about $30 \%$ since the 1970 s (Stewart et al., 2012). Cited explanations for this trend include the cost of fluid milk, concern over its caloric nature or a potential hormonal content, and the emergence of bottled water as an alternative beverage (Fisher et al., 2001; IDFA, 2013). To help stem the decline in fluid milk consumption, and to attract new consumers, the fluid milk which is available must be of the highest possible quality. Among other factors, milk quality is susceptible to damage from microbiological contamination, and from sub-optimal storage and transportation conditions, for example, temperature abuse or light exposure (Allen and Joseph, 1985).

Not surprisingly, microbial contamination and growth are major contributors to fluid milk quality. A major group of microorganisms responsible for fluid milk spoilage is represented by gram-negative bacteria, such as Pseudomonas sp., which are introduced into the product postprocessing (Schröder, 1984; Barcia et al., 1989); these organisms typically are responsible for sensory defects described as fruity, barny, and shrimpy, among others (Hayes et al., 2002). Gram-positive psychrotolerant sporeforming bacteria, which primarily originate from raw milk, can survive processing conditions in spore form and subsequently grow during refrigerated storage, potentially leading to microbial spoilage issues (Martin et al., 2012). Factors that influence the presence and outgrowth of spoilage microorganisms in the fluid milk continuum include cleaning and sanitation on the farm and in the processing facility (Simões et al., 2010; Masiello et al., 2014), dairy farm management practices (Masiello et al., 2014), animal health (Barbano et al., 2006), processing parameters (Gandy et al., 2008; Ranieri et al., 2009), and maintenance of the fluid milk cold chain from farm to consumer (Hankin, et al., 1977; De Jonghe et al., 2011). In addition to the contribution of microbial degradation, certain chemical factors have been shown to influence fluid milk quality, including the presence of heat-stable enzymes in raw milk produced by high levels of bovine somatic 
cells (Barbano et al., 2006) and light damage, which is induced by exposure of fluid milk to natural or artificial light (Aurand et al., 1977; Bradley, 1980).

Milk contains several photosensitive components, the most commonly cited being riboflavin (Singh et al., 1975; Cardoso et al., 2012), as well as porphyrin, chlorophyll, and others (Wold et al., 2005). When these photosensitizers are activated by natural or artificial light, the underlying photonic energy is transferred into the milk itself. This energy then initiates a chain reaction, whereby free-radical compounds and singlet oxygen are formed within the milk, inducing further chemical changes in neighboring molecules (Choe and Min, 2005). These chemical changes can include the generation of unwanted aromatic compounds, which have a profound negative effect on the perceived quality and consumer acceptance of milk (Chapman et al., 2002; Hayes et al., 2002). Ancillary effects of light exposure in milk may include degradation of the nutritional properties of the milk (Allen and Parks, 1979), and even an alteration in its visual characteristics (Lee et al., 1998). Previous research in this area has focused on the effect of fluorescent light (Jung et al., 1998; Chapman et al., 2002); however, there is a trend in the United States for retailers to replace fluorescent lights with light-emitting diode (LED) lighting in dairy display cases, due to economic and sustainability concerns. This study is the first to demonstrate the effects of LED lighting on consumer perception of fluid milk.

\section{MATERIALS AND METHODS}

\section{Sample Selection, Collection, and Transportation}

Initial selection of 4 New York State processing facilities to participate in this study was based on microbiological, chemical, and defect judging data collected by the Cornell Milk Quality Improvement Program (MQIP) through the Voluntary Shelf-Life Program (Carey et al., 2005; Martin et al., 2012). Based on these historical data, 2 plants with consistently high quality fluid milk (limited bacterial postprocessing contamination) and 2 plants with quality challenges (frequent occurrence of bacterial postprocessing contamination) were selected. The study was designed so that both fresh (FR) and near-code (NC) milk samples from the same plants could be evaluated at the same time by descriptive sensory panels and a large consumer panel. Hence, 2 sets of samples were collected from the same plants $14 \mathrm{~d}$ apart, so that samples from the first collection represented $\mathrm{NC}$ samples to be evaluated, whereas samples from the second collection represented the FR samples.
Each participating processing facility was instructed to collect $30.28 \mathrm{~L}$ (8 gallons) of skim and $2 \%$ milk from the middle of a single processing run, from the same filler nozzle, to reduce sampling variability. The samples were immediately put on ice and shielded from light in insulated coolers with a temperature control sample. Samples were collected by MQIP personnel on the day of processing and transported to the MQIP laboratory. Upon receipt, temperature controls were evaluated and all samples were coded with a randomly generated 3-digit code. Samples were stored at $5.5^{\circ} \mathrm{C}$, which represents a slightly abusive temperature consistent with consumer refrigerator temperatures (Kosa et al., 2007), in light-blocking coolers until further treatment and analysis.

Approximately 2 wk after the initial set of samples was collected, a second set of samples was obtained from 3 of the 4 processing facilities, using the procedures described above. One processing facility, representing one of the facilities with historical quality challenges, was excluded from further participation in the study due to premature spoilage caused by postprocessing contamination. Samples were transported protected from light at 0 to $4.0^{\circ} \mathrm{C}$ to both the site of sensory analysis (Department of Food Science, Cornell University, Ithaca, NY) and the site for consumer testing (Peryam and Kroll, White Plains, NY), for evaluation.

\section{Light Treatment}

Prior to selection of light treatment parameters, a survey of light exposure in retail dairy cases was performed to establish the most relevant lighting conditions. Based on the results of the survey demonstrating its popularity, LED lighting was chosen to perform light treatment. All light exposure treatments occurred within $24 \mathrm{~h}$ of sample collection for both the first and second sampling, meaning FR samples were evaluated soon after light exposure, whereas NC samples were stored for $\sim 13 \mathrm{~d}$ between exposure and testing. We exposed 14.14 L (4 gallons) of sample to $\sim 1,200 \mathrm{~lx}$ of $3,500 \mathrm{~K} \mathrm{LED} \mathrm{lighting} \mathrm{for} 4 \mathrm{~h}$. A control set of 14.14 L (4 gallons) of each fat level from each plant at both time points remained blocked from light exposure for the duration of the study. Immediately following light treatment, samples were returned to coolers and protected from light for the remainder of the study.

\section{Sensory Analysis}

Descriptive sensory evaluations (Stone and Sidel, 1998) were performed, by a trained panel, on 12 samples of reduced-fat $(2 \%)$ milk, and 11 samples of skim milk 
Table 1. Attributes rated by panelists for aroma, taste, aftertaste, with associated physical references used in training, all purchased at Wegmans (Ithaca, NY) unless indicated

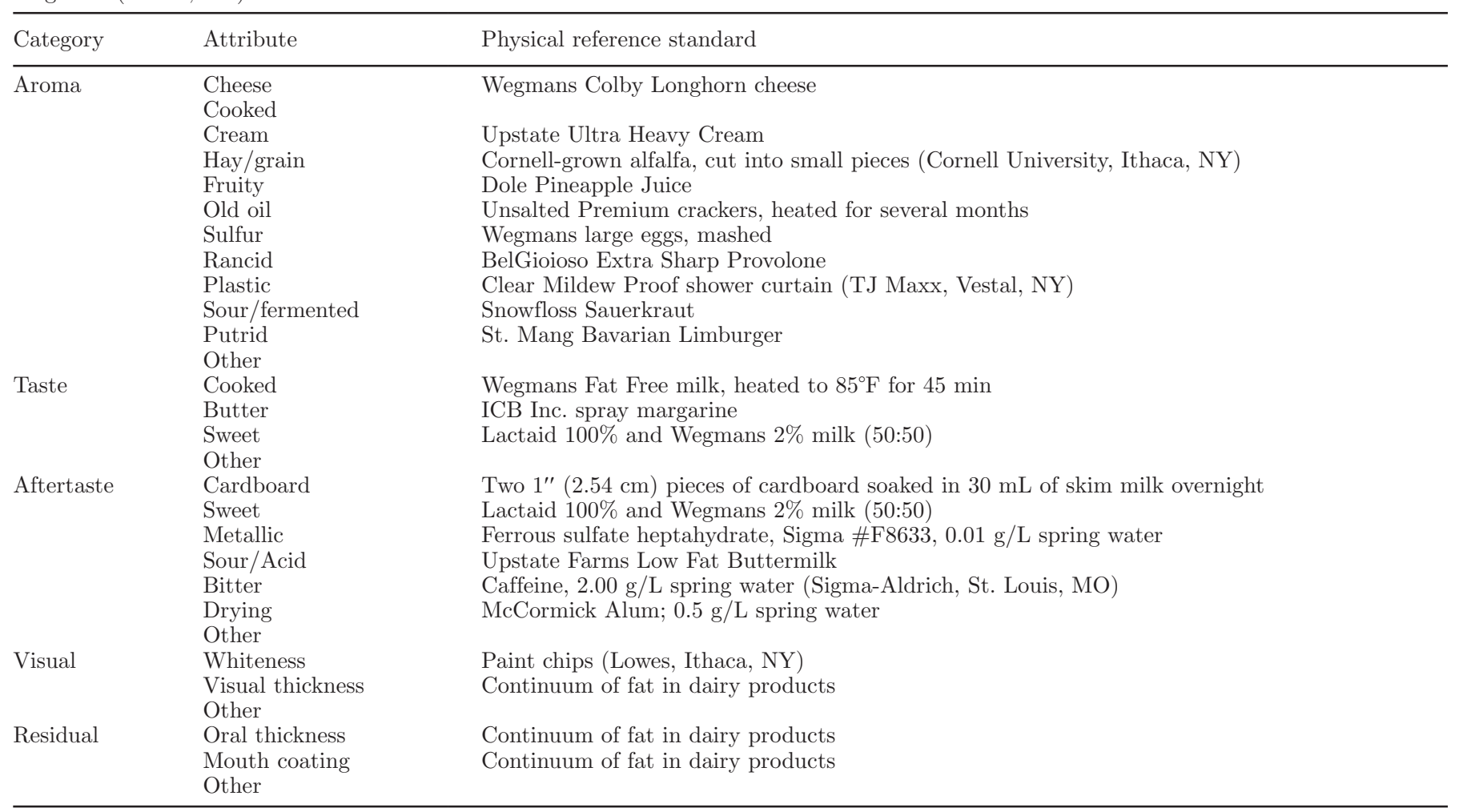

(after removal of one invalid sample provided with an elevated milk fat level). Sensory analysis was conducted in accordance with Cornell University's Institutional Review Board's guidelines. A total of 24 panelists (10 male, 14 female) were screened and selected from a pool of potential panelists, largely recruited from Cornell's staff and students, via testing of sensory acuity, replicability, and communication skills. Panelists were assigned to 1 of 2 descriptive panels (12 per panel, remaining with the same panel for the entire study), to limit the total number of samples assessed by each panelist, and to allow for inclusion of blind duplicates to aid with panelist assessment. Panels were trained over 27 to $33 \mathrm{~h}$ with sessions that included fine-tuning a modification of the ballot used by Fromm and Boor (2004), followed by identification and rating of various attributes present in both real-world and engineered samples. During training, panelists were calibrated using targets and ranges set using Compusense's feedback calibration method purported to halve training times (Findlay et al., 2007), and considered trained when able to repeatedly hit targets within \pm 0.5 points of the scale. A total of 24 attributes were selected, encompassing appearance, aroma (implying orthonasal evaluation before consumption), taste (implying ratings of both taste and retronasal olfaction within the mouth), aftertaste, and residual qualities of the samples (Table 1), but eliminating all hedonic aspects. The following were used as a continuum of dairy products to rate appearance and texture, with ratings for oral thickness given in parentheses: Wegmans Fat Free milk with $15 \%$ water (0.5), Wegmans Fat Free milk (1.0), Wegmans 2\% milk (3.0), Wegmans $2 \%$ milk plus Upstate Ultra Heavy Cream (25:75) (6.0), Wegmans $2 \%$ milk plus Upstate Ultra Heavy Cream (50:50) (7.0), and Upstate Ultra Heavy Cream (9.0). For whiteness, panelists made rankings of white color as compared with Valspar Ultra White Interior Satin Paint \#700624. Panelists were also permitted to write in and rate additional attributes, to avoid dumping into incorrect attribute ratings.

Ratings in both the training and the testing periods were taken using Compusense At-Hand sensory evaluation software (Compusense Inc., Guelph, ON, Canada), with panelists rating on Apple iPad Minis (Apple Inc., Cupertino, CA) on unstructured 10-point line scales. For testing, panelists were situated in individual booths under clear room lighting. Milk samples were swirled before testing, and then evaluated for visual qualities using blind-coded $90-\mathrm{mL}$ samples, before removing caps and sampling aromatic properties. After this, 
panelists sampled the milk, rated taste attributes of the milks, and finally resampled, and rated aftertaste, textural properties, and residual effects of the samples. All samples were served at 3 to $6^{\circ} \mathrm{C}$ and were evaluated in duplicate. Panelists were compensated $\$ 10$ per hour for training, and $\$ 20$ per hour for testing sessions. In testing sessions, panelists evaluated 6 samples over a 2-h morning session, with a second session following in the afternoon. Enforced breaks were inserted into the testing software to minimize fatigue. Data were analyzed with GraphPad Prism 5 (GraphPad software, La Jolla, CA), and linear mixed-models built with IBM SPSS (IBM, Endicott, NY), with statistical significance assumed at $P<0.05$. Attributes for which all of the samples were sub-threshold (i.e., $<0.5$ on the $0-10$ descriptive scale) were excluded from multidimensional analysis.

\section{Consumer Testing}

Following the collection of the second set of samples and subsequent light treatment, 11.36 L (3 gallons) of each treatment condition (fat level, light exposure, plant, and age) were packaged on ice in shipping coolers along with temperature control samples, and transported to the consumer analysis facility. A total of 304 respondents ( 150 per milk type) completed the consumer test, and were recruited as $50 \%$ male, $50 \%$ female with the following restrictions: (1) aged 18 to $65 \mathrm{yr},(2)$ no dietary restrictions or food allergies, (3) not a sufferer of diabetes, (4) neither pregnant nor nursing, and (5) drinkers of at least one glass of milk (of the milk type to be evaluated) in the past month. Panelists evaluated a single type of milk (skim or $2 \%$, based on habitual consumption), testing 12 samples of that type over a 2 -d period (6 samples per day). The 12 samples were served following a complete block design in which each sample was evaluated in each position in approximately the same number of cases. Each consumer test session lasted approximately $75 \mathrm{~min}$. Samples were served in a clear plastic cup (serving size per sample $118 \mathrm{~mL}$ ) at a temperature in the range of 3 to $6^{\circ} \mathrm{C}$. Consumer panelists completed a computer based self-administered questionnaire for each sample covering overall hedonic (9-point hedonic scale) and diagnostic [5-point just-about-right (JAR)] ratings on qualities of specific attributes. Appearance and aroma were evaluated before tasting. After tasting, panelists completed an overall hedonic rating, followed by purchase intent, and characteristic hedonic and diagnostic ratings (specifically aroma liking and strength JAR, appearance liking and whiteness JAR, purchase intent, texture liking, creaminess and thickness JAR, cream flavor and sweetness JAR, aftertaste liking and strength JAR, perceived quality rating, and freshness rating). The 6 samples for each test day were served sequentially based on the complete block design. At the end of evaluation on the second day, respondents answered demographic and usage questions.

\section{Microbiological Testing}

For microbiological testing, milk samples were inverted 25 times in accordance with Standard Methods for the Examination of Dairy Products (Laird et al., 2004 ) before a portion being aliquoted into sterile 2 oz vials for further testing. Samples were spiral plated on (1) standard plate count (SPC) agar (Difco, BD Biosciences, Franklin Lakes, NJ), followed by incubation at $32^{\circ} \mathrm{C}$ for $48 \mathrm{~h}$ for a total bacteria count (TBC); (2) SPC agar, followed by incubation at $6^{\circ} \mathrm{C}$ for $10 \mathrm{~d}$ for a psychrotrophic bacteria count (PBC); and (3) crystal violet tetrazolium agar, followed by incubation at $21^{\circ} \mathrm{C}$ for $48 \mathrm{~h}$ for total gram-negative bacteria count. Additionally, each sample was tested for coliform bacteria count on Coliform Petrifilm (3M, St. Paul, MN) according to manufacturers' instructions. Isolates representing each unique colony morphology on SPC (from both TBC and PBC tests) were sub-streaked for purity and subsequently frozen at $-80^{\circ} \mathrm{C}$ in $15 \%$ glycerol for further characterization. A total of 99 bacterial isolates from this study were collected and characterized using $16 \mathrm{~S}$ rDNA sequencing as previously described (Ivy et al., 2012). Further information on isolates collected from this study can be found at www.foodmicrobetracker.net.

\section{Chemical Evaluation}

Skim milk and $2 \%$ samples were evaluated for casein as a percentage of true protein $(\mathbf{C N} / \mathbf{T P})$ on the $\mathrm{FR}$ and NC time points, at a commercial testing laboratory (DairyOne, Ithaca, NY). Briefly, a portion of each sample was poured into a sterile $59.15-\mathrm{mL}(2-\mathrm{oz})$ vial and frozen and then thawed in pairs (FR and NC time point) and analyzed at the same time to minimize variance between analysis conditions. The CN/TP was determined using the Kjeldahl method as outlined in the Standard Methods for the Evaluation of Dairy Products (Hooi et al., 2004). For color assessment, Hunter L, a, and $\mathrm{b}$ values were determined as previously described (Adams and Barbano, 2013). Briefly, each sample was evaluated in duplicate using a Macbeth Color-Eye spectrophotometer (model 2020, Kollmorgen Instruments Corp., Newburgh, NY) at $24 \pm 1^{\circ} \mathrm{C}$ using a $1-\mathrm{cm}$ path length glass cuvette. Both skim and $2 \%$ samples 
were also tested for fat, true protein, anhydrous lactose, TS, SNF, and other solids by infrared analysis using a Lactoscope FT 400 (Delta Instruments, Drachten, the Netherlands) using optimized wavelengths as reported by Kaylegian et al. (2009). Calibration was performed using modified milk calibration samples (Kaylegian et al., 2006a,b). The reference methods for fat, true protein, lactose, and TS were Mojonnier (Barbano et al., 1988), direct Kjeldahl true protein (Barbano et al., 1991), enzymatic spectrophotometric analysis (Lynch et al., 2007), and forced-air oven drying (Clark et al., 1989), respectively. Solids-not-fat (TS minus fat) and other solids (SNF minus true protein) were calculated values. Milk fat globule size parameters d $(4,3)$ and $\mathrm{d}(0.9)$ were determined with a Mastersizer 2000 (Malvern, Westborough, MA). Component analysis, including $\%$ calcium, $\%$ phosphorus, $\%$ magnesium, $\%$ potassium, \% sodium, ppm iron, ppm zinc, ppm copper, ppm manganese, and ppm molybdenum was performed at a commercial testing laboratory (DairyOne) using inductively coupled argon plasma spectrophotometry.

\section{Statistical Analysis}

Data from the trained sensory panel and the consumer study were examined using external preference mapping (MacFie and Thomson, 1988) of consumer data onto sensory space (mapped with principal component analysis) to better understand the relationships among the properties that define the sensory space of the milk and determine drivers of liking. The complete original regression model included the linear and quadratic effects of each sensory dimension; however, only terms that were significant at the $90 \%$ confidence level were retained in the final model. The underlying sensory dimensions extracted from perceptual mapping were studied through multivariate factor analysis of the individual sensory attribute ratings, using XLSTAT statistical analysis software (Addinsoft, Paris, France). Cluster analysis determined dissimilarity by Euclidean distance using Ward's agglomeration method. Modeling was performed in the total respondent base and also on discrete consumers segments. The $\alpha$ level for the initial model building was set at $10 \%$, so as to include all terms approaching significance. Target products' sensory profiles were developed from each group of respondents, with target products representing combined factor scores falling within the sensory space of the products tested with the highest predicted overall liking rating. Generalized linear mixed regression model analysis of fixed and random effects of sensory data, with first-order interaction terms, was employed to isolate and analyze the effects of individual treatments across all samples.

\section{RESULTS}

\section{Chemical and Microbiological Analysis}

Overall, at the time of tasting, the TBC in all samples ranged from $2.41 \log \mathrm{cfu} / \mathrm{mL}$ to $8.31 \mathrm{log} \mathrm{cfu} / \mathrm{mL}$ with a mean of $4.68 \log \mathrm{cfu} / \mathrm{mL}$ (Table 2). The total aerobic plate count (APC) was below the Pasteurized Milk Ordinance (PMO) limit of $4.31 \mathrm{log} \mathrm{cfu} / \mathrm{mL}(20,000$ $\mathrm{cfu} / \mathrm{mL}$ ) for all $11 \mathrm{FR}$ samples as well as 7 of the 12 NC samples (Figure 1). Of the $18 \mathrm{FR}$ and NC samples below the PMO limit, all but one were found to have predominantly gram-positive microflora (Supplemental Table S1; http://dx.doi.org/10.3168/jds.2015-9603). This suggests that significant PPC with gram-negative bacteria did not occur in the $7 \mathrm{NC}$ samples with TBC $<20,000 \mathrm{cfu} / \mathrm{mL}$. Five NC samples had TBC above the PMO limit at the time of tasting. Two of these samples had TBC $>8 \log \mathrm{cfu} / \mathrm{mL}$ and were found to have gramnegative contamination, specifically Pseudomonas spp., strongly implying postprocessing contamination; the other 3 samples had TBC of $4.66,4.79$, and $5.00 \mathrm{cfu} /$ $\mathrm{mL}$.

Although plant of origin was initially employed as a surrogate for quality, it became clear in both microbiological and hedonic analyses that historical quality ratings were not consistent across the samples provided, and in fact the plant with the best historical quality ratings performed poorly as a whole. Comparison of TBC for $\mathrm{NC}$ samples to their corresponding FR samples (Figure 1) showed 2 instances where the NC samples had $>4 \log$ higher TBC than the corresponding FR samples (e.g., plant $\mathrm{C}$ lighted skim, which showed gram-negative contamination in the $\mathrm{NC}$ sample). Interestingly, for plant $\mathrm{C}$, other samples displayed virtually no difference in TBC between FR and $\mathrm{NC}$ samples (e.g., plant $\mathrm{C}$ non-light exposed $2 \%$, negative for gram-negative contamination). Psychrotolerant bacteria count at the day of tasting showed a similar pattern to the APC, with the NC samples ranging from less than detection $(<1 \log \mathrm{cfu} / \mathrm{mL})$ to $7.98 \log \mathrm{cfu} / \mathrm{mL}$ and a mean of $3.60 \log \mathrm{cfu} / \mathrm{mL}$ (Table 2). Interestingly, plant A lighted $2 \% \mathrm{NC}$ showed no evidence of gramnegative contamination, but displayed counts $>20,000$ $\mathrm{cfu} / \mathrm{mL}$, indicative of psychrotolerant sporeformer outgrowth (as supported by isolation of Paenibacillus from this sample, see Supplemental Table S1, http//dx.doi. org/10.3168/jds.2015-9603; Figure 1).

The CN/TP ratio, an indicator of proteolysis, was significantly correlated with APC $\left(\mathrm{R}^{2}: 0.82, P=0.003\right)$. It was also significantly correlated with gram-negative count $\left(\mathrm{R}^{2}: 0.77, P=0.03\right)$, whereas the correlation between $\mathrm{CN} / \mathrm{TP}$ ratio and psychrotolerant bacteria count approached significance $\left(\mathrm{R}^{2}: 0.60, P=0.055\right)$. Sensory 
descriptors relating to the various aspects of viscosity of the samples (visual thickness, oral thickness, mouth coating) correlated well $\left(\mathrm{R}^{2}>0.8, P<0.05\right)$ with several instrumental measurements, such as colorimeter readings and infrared measures. Instrumental readings of particle size correlated with sensory ratings of visual and oral thickness and of mouth coating (Figure 2). Cream aroma, butter taste, and to a lesser extent, sweet aftertaste, were detected by the panelists consistently and correlated with colorimeter and infrared readings (Figure 2). Only ratings of sour/fermented and putrid odors correlated with readings of APC and PBC counts, tightly with PBC and putrid (Figure 2). No sensory attributes correlated with any of the ionic measurements (e.g., minerals, trace metals), although this was possibly due to the low ion concentration in all samples.

For attributes that breached levels considered threshold, full results of the mixed model analyses as well as various important interaction terms are summarized in Table 3 . The sensory properties of products of differing fat content and plant of origin differed across several attributes. Product age was significantly correlated with plastic and putrid aroma, and with the visual thickness of samples. Light treatment resulted in broad sensory variation across samples, in taste, aftertaste, aroma, and textural properties. Second-order interactions were significant between fat content and light treatment, in the models built for putrid aroma, oral thickness, and mouth coating. Between product age and light treatment, significant variation was observed in cream and in plastic aroma. Between age and fat content, ratings of cream aroma, visual and oral thickness, and mouth coating displayed statistically significant variation.

\section{Multidimensional Analysis}

As the sensory properties of the 23 viable samples (12 reduced fat and 11 skim) tended to separate in sensory space by fat content when plotted together, separate multivariate principal component analyses were performed on the $2 \%$ samples and skim samples (Chapman et al., 2001). Around $85 \%$ of the variation between skim samples was accounted for by the first 4 dimensions produced by the analysis, representing (1) white and thick; (2) lingering sweet, grassy, and cooked; (3) plastic aroma and sweet; and (4) putrid and mouthdrying. Samples separated well in this multidimensional space, with the plant $\mathrm{C}$, lighted, NC sample standing out as being high in "white and thick" and "putrid and drying," and both plant A non-light-exposed samples notably low in "white and thick" and high in "putrid and drying." Most of the variation (94\%) between $2 \%$ fat milk samples was accounted for by the first 5 dimensions of analysis, representing (1) sweet and creamy

Table 2. Summary of descriptive statistics for microbiological and chemical tests performed on 23 milk samples representing skim and $2 \%$ fat milk from 3 New York state fluid milk processors, with 2 light treatments and at 2 time points

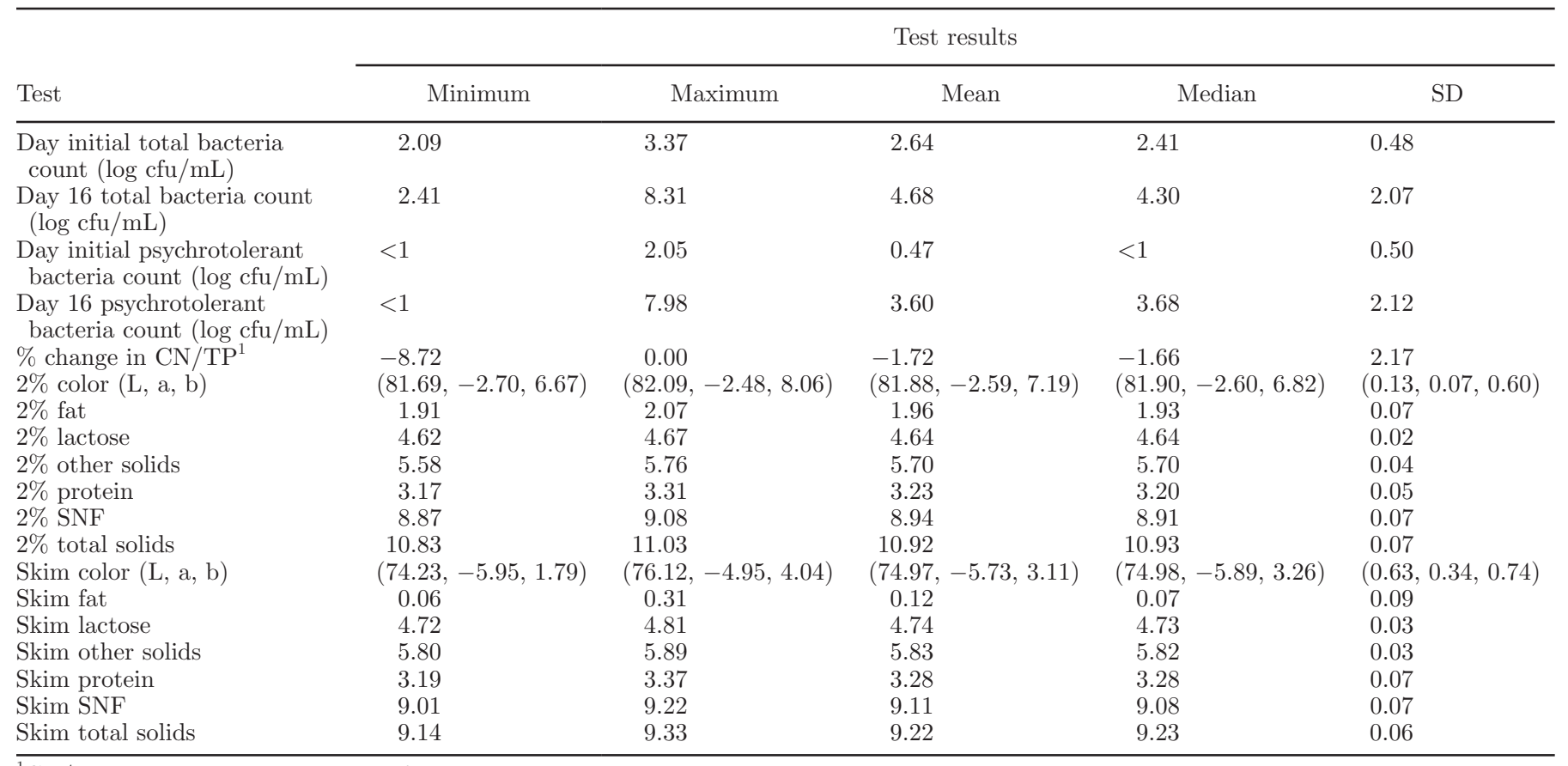

${ }^{1} \mathrm{CN} / \mathrm{TP}=$ casein as a percentage of true protein. 
to sour and putrid, (2) drying to mouth coating and thick, (3) whiteness, (4) buttery, and (5) plastic. The samples separated well in the sensory space; however, there were a few outliers, with the sample from plant
$\mathrm{B}$, nonlight exposed, NC standing out as high in "sour/ fermented and putrid," plant C, non-light-exposed, NC being high in "drying" and low in "whiteness," and the 2 samples from plant B, lighted high in "buttery."

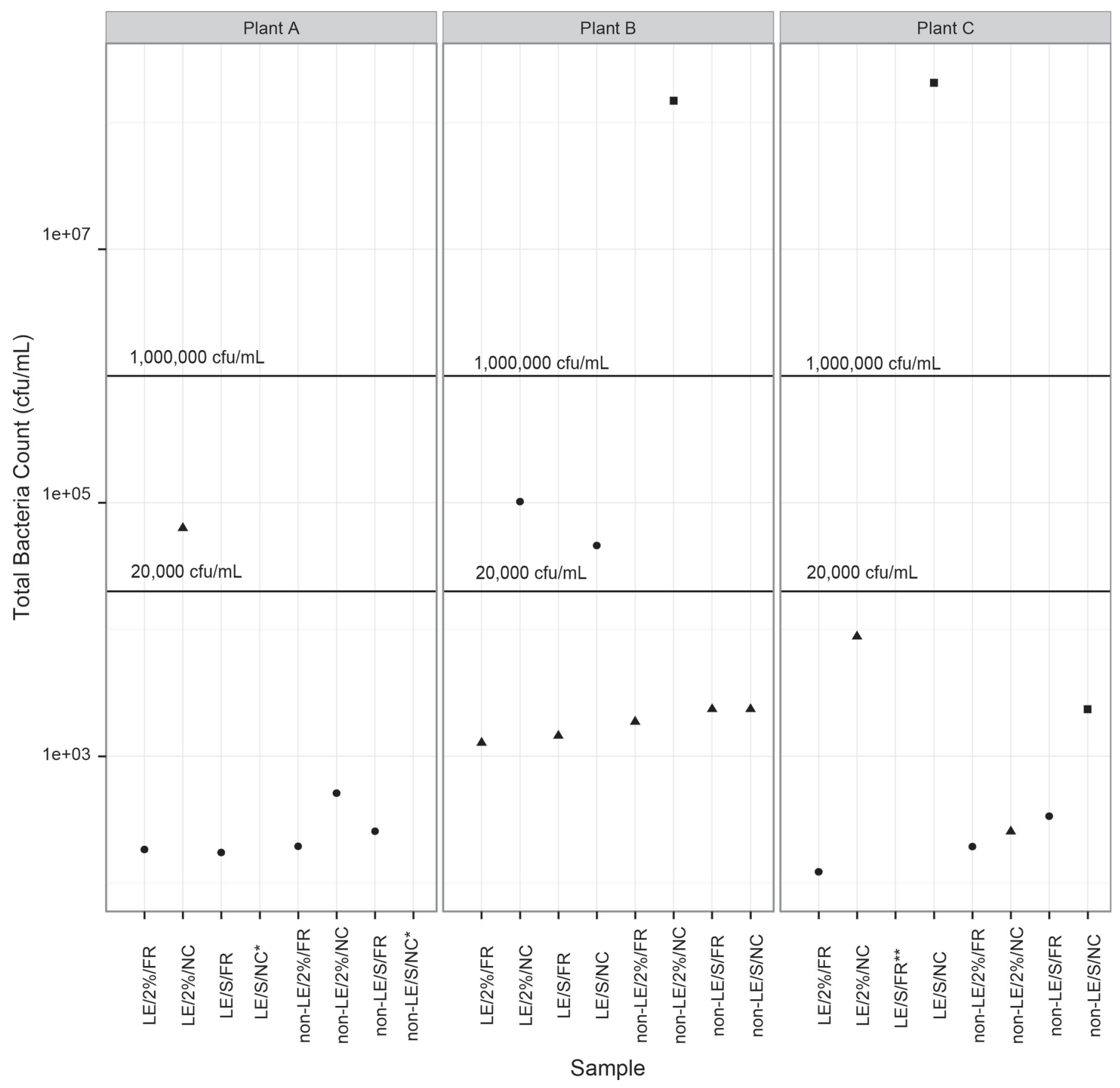

Figure 1. Total bacteria counts for samples of light treated and non-light treated, skim and $2 \%$ fat, and fresh and near code milk on the day of quantitative descriptive analysis tasting. Crystal violet tetrazolium agar contamination was used as an indicator of the presence of gram-negative bacteria, where $\boldsymbol{\Lambda}$ indicates no gram-negative bacteria (negative), $\bullet$ indicates samples with $>10 \mathrm{cfu} / \mathrm{mL}$ but $<400 \mathrm{cfu} / \mathrm{mL}$ gramnegative bacteria (marginal), and $\mathbf{\square}$ indicates samples with $>400 \mathrm{cfu} / \mathrm{mL}$ gram-negative bacteria (positive). Horizontal lines designate 20,000 and 1,000,000 cfu/mL. Sample code is arranged in the following format: light exposure/fat level/age, where LE = light exposed; non-LE = non light exposed; $\mathrm{S}=$ skim; $\mathrm{FR}=$ fresh; and $\mathrm{NC}=$ near code. ${ }^{*}$ indicates samples where total bacteria count is missing because of a laboratory error. ${ }^{* *}$ indicates sample where total bacteria count is missing because the sample was dropped from analysis. 


\begin{tabular}{|c|c|c|c|c|c|c|c|c|c|c|c|c|c|c|c|c|c|c|c|}
\hline & $\begin{array}{l}0 \\
0 \\
z \\
0,0 \\
0 \\
0\end{array}$ & $\left|\begin{array}{c}0 \\
m \\
0 \\
0.0 \\
0 \\
0\end{array}\right|$ & 点 & 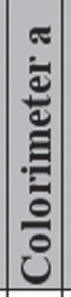 & 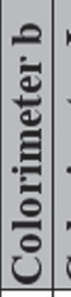 & 园 & 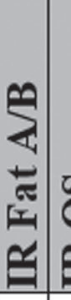 & 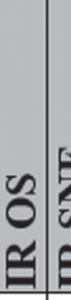 & 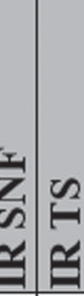 & ع & 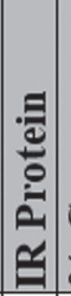 & $\begin{array}{l}\tilde{0} \\
0 \\
0\end{array}$ & $\begin{array}{l}4 \\
0\end{array}$ & $\sum_{0}^{\infty}$ & $\begin{array}{l}\tilde{z} \\
\mathrm{z}^{\circ} \\
0^{\circ}\end{array}$ & $\begin{array}{l}0 \\
0 \\
0 \\
0\end{array}$ & 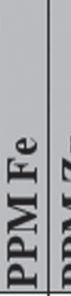 & 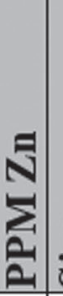 & $\stackrel{\pi}{5}$ \\
\hline Cheese & & & & & & & & & & & & & & & & & & & \\
\hline Cooked & & & & & & & & & & & & & & & & & & & \\
\hline Cream & & & & & & & & & & & & & & & & & & & \\
\hline Fruit & & & & & & & & & & & & & & & & & & & \\
\hline Hay/Gr & & & & & & & & & & & & & & & & & & & \\
\hline Old Oil & & & & & & & & & & & & & & & & & & & \\
\hline Plastic & & & & & & & & & & & & & & & & & & & \\
\hline Putrid & & & & & & & & & & & & & & & & & & & \\
\hline Rancid & & & & & & & & & & & & & & & & & & & \\
\hline Sulfur & & & & & & & & & & & & & & & & & & & \\
\hline Sour/Ferm & & & & & & & & & & & & & & & & & & & \\
\hline Whiteness & & & & & & & & & & & & & & & & & & & \\
\hline Vis Thick & & & & & & & & & & & & & & & & & & & \\
\hline Butter & & & & & & & & & & & & & & & & & & & \\
\hline Cooked & & & & & & & & & & & & & & & & & & & \\
\hline Sweet & & & & & & & & & & & & & & & & & & & \\
\hline Bitter & & & & & & & & & & & & & & & & & & & \\
\hline Cardboard & & & & & & & & & & & & & & & & & & & \\
\hline Drying & & & & & & & & & & & & & & & & & & & \\
\hline Metallic & & & & & & & & & & & & & & & & & & & \\
\hline Sweet & & & & & & & & & & & & & & & & & & & \\
\hline Sour/acid & & & & & & & & & & & & & & & & & & & \\
\hline Oral Thick & & & & & & & & & & & & & & & & & & & \\
\hline Mouth Coat & & & & & & & & & & & & & & & & & & & \\
\hline
\end{tabular}

Figure 2. Matrix displays correlations between attribute ratings (y-direction) and instrumental readings (x-direction). Color represents Pearson correlation squared $\left(\mathrm{R}^{2}\right)$, with light gray indicating a correlation from 0.4 to 0.59 , dark gray 0.6 to 0.79 , and black above 0.8 . Data represent quantitative descriptive analysis ratings versus instrumental measures. $\mathrm{APC}=$ aerobic plate count; $\mathrm{PBC}=$ psychrotolerant bacteria count; $\mathrm{CN} / \mathrm{TP}=$ casein as a percentage of true protein; IR = infrared; OS = other solids; size = particle size.

\section{Consumer Analysis}

Overall, the results of analysis from consumer data highlight the effects of light on the milk when compared with unexposed or "shielded" milk. On a 9-point hedonic scale, consumers rated light-exposed FR samples almost a point lower than non-light-exposed FR samples (6.8 vs. 5.9), as well as 0.5 points lower when comparing all lighted samples to the non-light-exposed samples (6.7 vs. 6.2). The non-light-exposed samples decreased by just 0.2 points with age (6.6 vs. 6.4$)$. Thus, the decrease in liking from light exposure appeared temporary in nature, with liking of the exposed samples increasing after the storage period (see Figure 3). The initial light exposure effects were so powerfully negative that the $\mathrm{NC}$ sample was preferred in every case to the FR sample regardless of microbial defects, when considering only the light-exposed samples. This was presumably due 
Table 3. Linear mixed model analysis of descriptive sensory ratings by treatment, with first-order interactions

\begin{tabular}{|c|c|c|c|c|c|c|c|c|c|c|c|c|}
\hline \multirow{2}{*}{\multicolumn{2}{|c|}{ Treatment and condition (sample size in parentheses) }} & \multicolumn{11}{|c|}{ Descriptive sensory attributes and ratings ${ }^{1}$} \\
\hline & & Cream & Plastic & Putrid & White & $\begin{array}{c}\text { Visual } \\
\text { thickness }\end{array}$ & Cooked & $\begin{array}{c}\text { Sweet } \\
\text { taste }\end{array}$ & Drying & $\begin{array}{c}\text { Sweet } \\
\text { aftertaste }\end{array}$ & $\begin{array}{c}\text { Oral } \\
\text { thickness }\end{array}$ & $\begin{array}{l}\text { Mouth } \\
\text { coating }\end{array}$ \\
\hline \multirow[t]{3}{*}{ Fat level } & $2 \%(12)$ & 0.7370 & 0.2390 & 0.2980 & 4.8900 & 3.7310 & 0.4920 & 1.6280 & 0.1870 & 1.0180 & 3.4710 & 2.8040 \\
\hline & Skim (12) & 0.2470 & 0.3710 & 0.2430 & 3.8880 & 2.3340 & 0.3760 & 1.4070 & 0.3740 & 0.6910 & 2.2070 & 1.6880 \\
\hline & $P$-value & 0.0000 & 0.0118 & 0.4448 & 0.0000 & 0.0000 & 0.0783 & 0.0028 & 0.0001 & 0.0000 & 0.0000 & 0.0000 \\
\hline \multirow[t]{3}{*}{ Age } & Fresh (12) & 0.5360 & 0.3780 & 0.1980 & 4.3570 & 3.1060 & 0.4230 & 1.5650 & 0.2870 & 0.9080 & 2.8740 & 2.2580 \\
\hline & Near code $(12)$ & 0.4490 & 0.2310 & 0.3430 & 4.4200 & 2.9590 & 0.4450 & 1.4700 & 0.2740 & 0.8000 & 2.8030 & 2.2350 \\
\hline & $P$-value & 0.1626 & 0.0052 & 0.0431 & 0.2743 & 0.0077 & 0.7339 & 0.2012 & 0.7809 & 0.0769 & 0.1946 & 0.6839 \\
\hline \multirow[t]{4}{*}{ Plant } & A (8) & 0.3890 & 0.3410 & 0.2720 & 4.1390 & 2.9300 & 0.4950 & 1.5950 & 0.2490 & 0.9400 & 2.7620 & 2.1300 \\
\hline & B (8) & 0.4580 & 0.2660 & 0.2730 & 4.3460 & 2.8520 & 0.3960 & 1.3480 & 0.2610 & 0.6870 & 2.6390 & 2.0840 \\
\hline & $\mathrm{C}(8)$ & 0.6290 & 0.3070 & 0.2660 & 4.6810 & 3.3150 & 0.4100 & 1.6100 & 0.3310 & 0.9360 & 3.1160 & 2.5250 \\
\hline & $P$-value & 0.0054 & 0.5010 & 0.9965 & 0.0000 & 0.0000 & 0.4208 & 0.0052 & 0.3101 & 0.0006 & 0.0000 & 0.0000 \\
\hline \multirow{3}{*}{ Light treatment } & Non light exposed (12) & 0.3250 & 0.2360 & 0.3570 & 4.2310 & 2.9270 & 0.4560 & 1.3910 & 0.2870 & 0.7870 & 2.8020 & 2.1810 \\
\hline & Light exposed (12) & 0.6590 & 0.3740 & 0.1840 & 4.5470 & 3.1380 & 0.4120 & 1.6440 & 0.2740 & 0.9220 & 2.8760 & 2.3120 \\
\hline & $P$-value & 0.0000 & 0.0093 & 0.0165 & 0.0000 & 0.0002 & 0.5061 & 0.0007 & 0.7806 & 0.0285 & 0.1788 & 0.0254 \\
\hline \multirow{5}{*}{ Fat level $\times$ light interaction } & $2 \%$ non light exposed $(6)$ & 0.5210 & 0.1860 & 0.4580 & 4.7590 & 3.6770 & 0.5330 & 1.5220 & 0.2340 & 0.9390 & 3.5190 & 2.8290 \\
\hline & $2 \%$ light exposed $(6)$ & 0.9540 & 0.2910 & 0.1370 & 5.0210 & 3.7840 & 0.4510 & 1.7340 & 0.1400 & 1.0960 & 3.4230 & 2.7800 \\
\hline & Skim non light exposed (6) & 0.1290 & 0.2860 & 0.2550 & 3.7030 & 2.1770 & 0.3790 & 1.2600 & 0.3400 & 0.6350 & 2.0850 & 1.5330 \\
\hline & Skim light exposed (6) & 0.3650 & 0.4560 & 0.2320 & 4.0720 & 2.4920 & 0.3720 & 1.5540 & 0.4070 & 0.7470 & 2.3300 & 1.8430 \\
\hline & $P$-value $P$ (a) & 0.1302 & 0.5567 & 0.0439 & 0.3825 & 0.0734 & 0.5862 & 0.5928 & 0.1073 & 0.7245 & 0.0031 & 0.0033 \\
\hline \multirow{5}{*}{ Age $\times$ light interaction } & Fresh non light exposed (6) & 0.3010 & 0.2230 & 0.3350 & 4.1530 & 2.9730 & 0.4860 & 1.3780 & 0.3010 & 0.8510 & 2.8210 & 2.1560 \\
\hline & Fresh light exposed (6) & 0.7700 & 0.5330 & 0.0620 & 4.5610 & 3.2390 & 0.3590 & 1.7520 & 0.2730 & 0.9650 & 2.9280 & 2.3610 \\
\hline & Near code non light exposed $(6)$ & 0.3490 & 0.2490 & 0.3790 & 4.3090 & 2.8820 & 0.4260 & 1.4040 & 0.2740 & 0.7220 & 2.7820 & 2.2060 \\
\hline & Near code light exposed (6) & 0.5480 & 0.2140 & 0.3070 & 4.5320 & 3.0360 & 0.4640 & 1.5360 & 0.2740 & 0.8780 & 2.8250 & 2.2630 \\
\hline & $P$-value & 0.0306 & 0.0010 & 0.1583 & 0.1092 & 0.3125 & 0.2085 & 0.1014 & 0.7686 & 0.7306 & 0.5575 & 0.1992 \\
\hline \multirow{5}{*}{ Age $\times$ fat level interaction } & Fresh $2 \%(6)$ & 0.6670 & 0.2750 & 0.2270 & 4.8200 & 3.7330 & 0.5000 & 1.6520 & 0.2020 & 1.0670 & 3.4160 & 2.7420 \\
\hline & Fresh skim (6) & 0.4040 & 0.4810 & 0.1700 & 3.8940 & 2.4800 & 0.3450 & 1.4770 & 0.3720 & 0.7500 & 2.3330 & 1.7740 \\
\hline & Near code $2 \%(6)$ & 0.8080 & 0.2030 & 0.3680 & 4.9590 & 3.7290 & 0.4840 & 1.6040 & 0.1720 & 0.9680 & 3.5250 & 2.8670 \\
\hline & Near code skim (6) & 0.0890 & 0.2600 & 0.3170 & 3.8810 & 2.1890 & 0.4060 & 1.3360 & 0.3760 & 0.6320 & 2.0810 & 1.6020 \\
\hline & $P$-value & 0.0003 & 0.1529 & 0.9675 & 0.1889 & 0.0094 & 0.5606 & 0.5294 & 0.7245 & 0.8726 & 0.0010 & 0.0103 \\
\hline
\end{tabular}




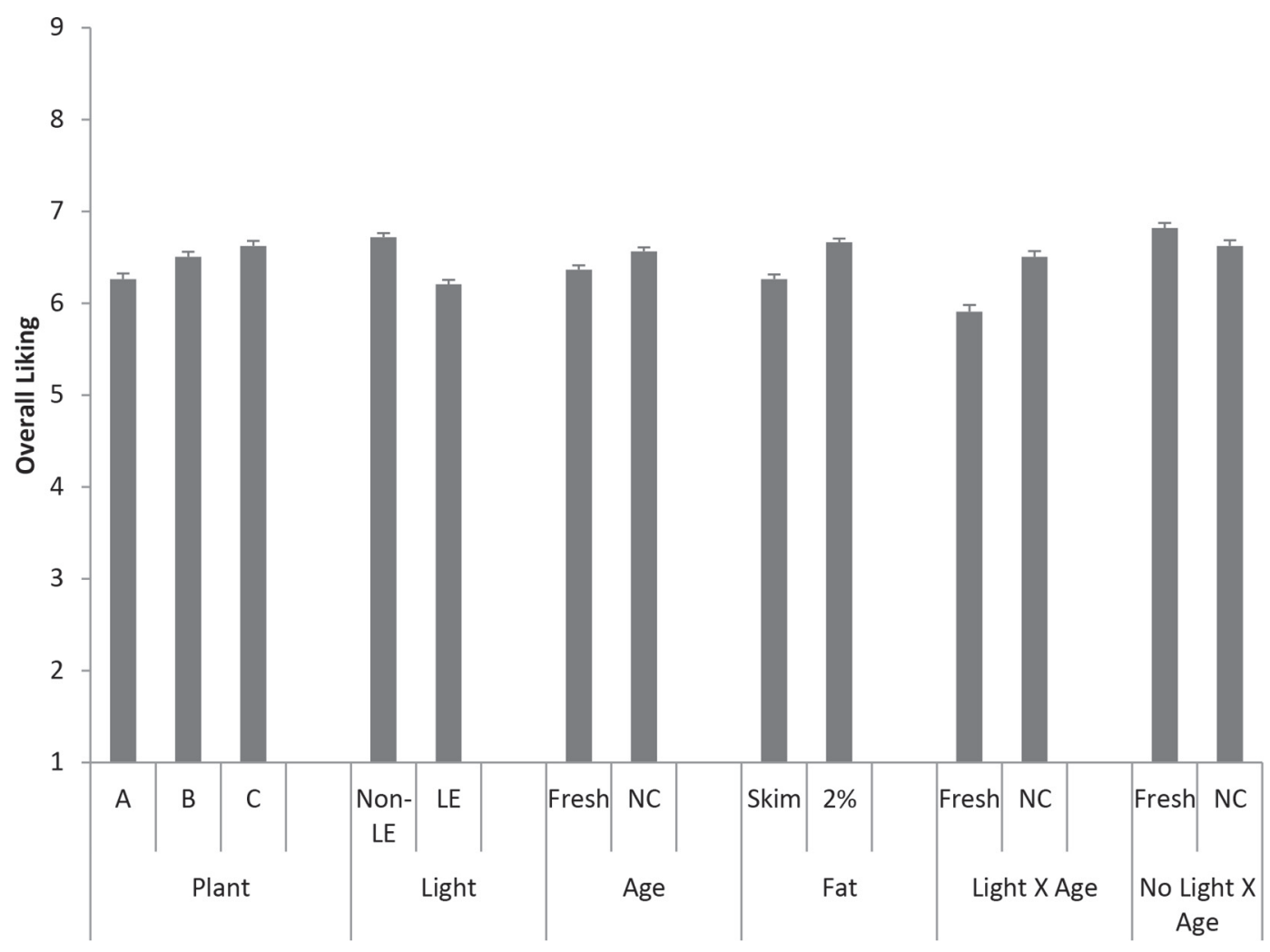

Figure 3. Overall effects of treatments across all samples as determined by consumer panels. Vertical axis represents overall liking on a 9-point hedonic scale. Horizontal axis represents treatment. Bars represents the mean values of overall liking determined by the consumer panel of $\sim 150$ for each fat level, where $1=$ dislike extremely; $2=$ dislike very much; $3=$ dislike moderately; $4=$ dislike slightly; $5=$ neither like nor dislike; $6=$ like slightly; $7=$ like moderately; $8=$ like very much; and $9=$ like extremely. LE $=$ light exposed; non-LE $=$ non light exposed; $\mathrm{NC}=$ near code.

to the freshly light-exposed samples having no time for off aromas to disperse. This is demonstrated when observing the dramatic drop-off in liking between freshly light exposed samples and those exposed several days previously, when examining the first-order interaction in the models built between light and age. Plant $\mathrm{C}$ was clearly preferred by consumers, with plant A being the least popular (see Figure 3), and the panel preferred $2 \%$ milks to skim. Due to the inherent differences between $2 \%$ and skim milk, data analysis was carried out on the 2 milkfat levels independently.

\section{Skim Milk Samples}

Substantial differences in overall liking were found among the skim treatments (ranging from 5.2 to 6.9). Using a mixed-model analysis, consumer liking of skim milk was found to be affected by each of the treatments $(P<0.0001$ for light and plant, $P=0.0004$ for sample age). Interactions between plant and sample age $(P=$ $0.039)$, plant and light treatment $(P=0.014)$, and light treatment and age $(P<0.0001)$ were also significant (Figure 3). Most consumer attributes were highly cor- related with overall liking, with perceptions of taste $\left(\mathrm{R}^{2}=0.982\right)$, aftertaste $\left(\mathrm{R}^{2}=0.956\right)$, freshness $\left(\mathrm{R}^{2}=\right.$ $0.948)$, and quality $\left(\mathrm{R}^{2}=0.973\right)$ strongly correlated with liking. Light-exposed skim milk samples were liked substantially less (liking mean $=6.0$ ) than non-lightexposed samples (liking mean $=6.5$ ). Analysis also indicated that light-exposed skim samples approaching code were rated higher (mean liking $=6.4$ ) than corresponding light-exposed fresh samples (mean liking $=5.7)$. Conversely, when compared with non-lightexposed FR samples (mean liking $=6.6$ ), non-lightexposed NC skim samples showed lower liking scores $($ mean liking $=6.5)$.

The liking for a specific quality factor (flavor, texture, freshness, and quality) tended to be highly correlated with ratings for overall liking. As a general rule for skim samples, the less hedonically liked products tended to be the ones that had been exposed to light (liking mean 6.2 vs. 6.7). Cluster analysis (Qannari et al., 1997) identified 2 segments of consumers with differing patterns of liking across the 11 skim milk samples. Segment 1 ( $\mathrm{n}=94,63 \%$ of total respondents) showed moderate liking ratings (mean liking score across all samples $=$ 

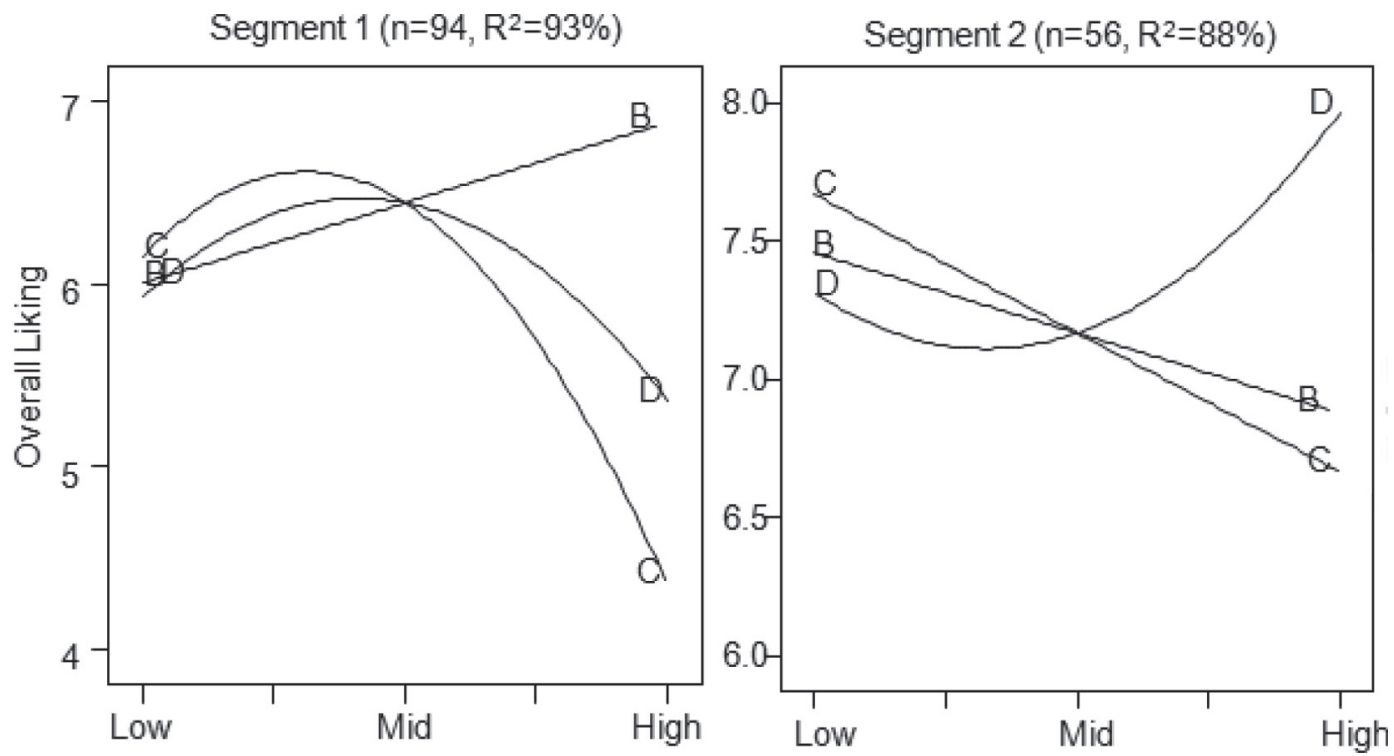

Figure 4. Key drivers of liking of individual consumer segments for skim milk. Factor ranges: (A) white and thick; (B) lingering, sweet, hay/ grass, and cooked; (C) plastic aroma and sweet; (D) putrid and drying. Segments agreed on a preference for low "plastic aroma and sweet," whereas "white and thick" was not important to either. However, segment 1 ( $\mathrm{n}=94)$ preferred a higher level of "lingering sweet, hay/grass, and cooked," and a lower "putrid and drying" than segment $2(\mathrm{n}=56)$. Only factors that were significant predictors of consumer acceptance are shown.

5.7), following closely the trend exhibited by the total respondent base $(\mathrm{n}=150)$. This segment showed a statistical preference for skim milk from plants B (mean liking score $=5.8)$ and $\mathrm{C}$ (mean liking score $=6.2$ ) over plant A (mean liking score $=5.2$ ), and lower ratings of liking for the light-exposed condition (mean liking score $=5.4$ ) than for non-light-exposed (mean liking score $=7.1)$. Segment $2(\mathrm{n}=56,37 \%$ of total respondents $)$ was somewhat less discerning, and reported high liking ratings for all of the treatments $($ mean $=7.4)$, but still rated the light-exposed samples with lower liking $($ mean $=7.1)$ than non-light-exposed $($ mean $=7.6)$. Among the shielded (non-light-exposed) skim samples, no preference was shown for plant of origin. Although both segments exhibited a strong negative correlation between liking and both plastic aroma and sweet taste ratings from the quantitative descriptive analysis ( $\mathrm{r}>$ -0.5 ), segment 2 also correlated liking negatively with hay/grain aroma, and surprisingly, positively with putrid aroma. All other attribute correlations were below 0.5 .

Overall consumer liking for the skim treatments was also correlated with sensory properties as determined by quantitative descriptive analysis $\left(R^{2}=0.90\right)$. Most importantly, in the model for skim samples was a low to mid-level rating of "plastic aroma" and "sweet"; however, most of the variation in the samples was due to plastic aroma, suggesting this was where most of the consumer reaction originated. The segments were found to have alternate key drivers of consumer liking (Figure 4), with segments 1 and 2 agreeing on their preference for low "plastic aroma and sweet" and that any level of "white and thick" within the observed ranges was acceptable; however, segment 1 preferred high "lingering sweet, hay/grass, and cooked" and a low level of "putrid and drying," whereas segment 2 preferred low "lingering sweet, hay/grass, and cooked," and surprisingly, a slightly higher level of "putrid and drying."

\section{$2 \%$ Samples}

Overall consumer liking for $2 \%$ samples (ranging from 6.0 and 7.1 on a 9 -point scale) was significantly higher $(P=0.04)$ than for skim samples (5.2 to 6.9). Among the $2 \%$ milk samples only a light exposure condition $(P<0.0001)$ showed a significant effect on consumer liking with no effect for plant $(P=0.784)$ or sample age $(P=0.232)$. Similar to skim milk, consumers liked $2 \%$ samples that were not light exposed more than those that were light exposed. Interaction between the plant of origin and age of samples $(P=0.027)$, and the light treatment and age $(P<0.0001)$ were significant in the model for $2 \%$; unlike for the skim samples, the interaction between plant and light treatment was not $(P$ $=0.382$ ). Other hedonic ratings of specific attributes mirrored the results from overall liking ratings for $2 \%$ samples, as only non-light-exposed samples showed significant differences between treatments. Consistent 
with findings for skim milk, the majority of consumer attributes were highly correlated with overall liking of $2 \%$ (slightly less so for appearance). Interestingly, consumers were somewhat more forgiving and penalized $2 \%$ milk less severely than skim for light exposure, possibly due to the inherent higher degree of liking for the product, or for its innate white, thick, creamy appearance. The strongest correlation between sensory attributes from the trained panel and consumer liking of $2 \%$ milk was a negative correlation with plastic aroma $(r \geq 0.75)$, with a negative correlation for cream aroma also relatively important $(0.50 \leq \mathrm{r}<0.75)$. All other attributes were only weakly correlated $(\mathrm{r}<0.50)$.

Cluster analysis again identified 2 distinct segments with different liking patterns across the $2 \%$ samples. Segment $1(\mathrm{n}=46,30 \%)$ displayed a moderate liking for most products (average liking score across all samples $=5.4)$, liking the non-light-exposed FR samples most (mean liking $=6.0)$. Segment $2(\mathrm{n}=108,70 \%)$ showed a higher liking score as a whole for all of the $2 \%$ samples (average liking score across all samples $=$ 7.1), and rated the 3 light-exposed FR samples lowest in overall liking (mean liking $=6.6$ ) and the 3 light-exposed $\mathrm{NC}$ samples the next lowest (mean liking $=7.1$ ).

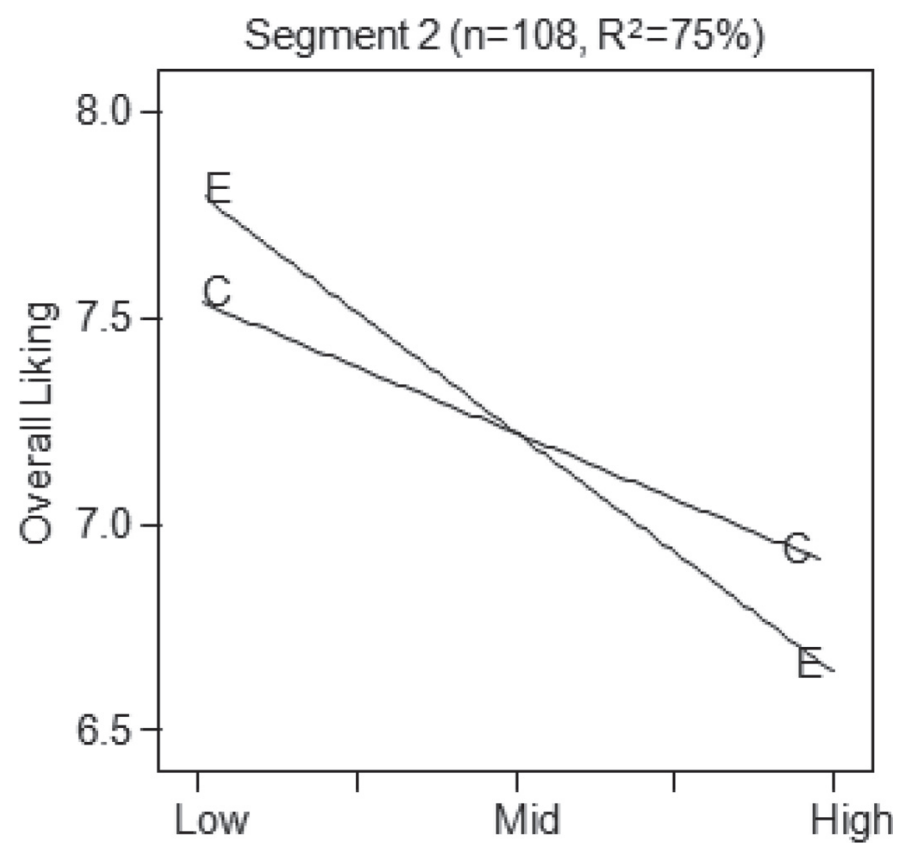

Figure 5. Key drivers of liking of the larger consumer segment 2 for $2 \%$ milk. Factor ranges: (A) sweet and creamy to sour/fermented and putrid, (B) drying to thick and coating, (C) whiteness, (D) buttery, (E) plastic aroma. Although no model converged at 90\% confidence for segment $1(\mathrm{n}=46)$, possibly due to its smaller size, segment 2 (n $=108$ ) showed clearly that consumers preferred low "plastic aroma" and low "whiteness" in their milk, similarly to the drivers of the total respondent base. Only factors that were significant predictors of consumer acceptance are shown.
Otherwise the $2 \%$ liking ratings were similar between segments, with segment 1 preferring non-light-exposed FR product (mean liking $=6.0$ ) over all other treatments (mean liking $=5.3$ ), and segment 2 preferring non-light-exposed products (mean liking $=7.4$ ) over the light-treated products (mean liking $=6.8$ ), but preferring $\mathrm{NC}$ products (mean liking $=7.2$ ) over $\mathrm{FR}$ (mean liking $=7.0$ ).

Overall liking for the $2 \%$ samples was also correlated with sensory properties determined by the trained panel $\left(R^{2}=0.73\right)$; however, significant differences in overall liking were evident among the treatments. Most important was a low plastic aroma, with low whiteness the next most important key driver. Both of these characteristics are related to light exposure. The 2 segments also showed differing drivers of liking in our analysis, with response from segment 1 most correlated with a low plastic aroma $(0.50 \leq \mathrm{r}<0.75)$, with all other attributes less important $(\mathrm{r}<0.50)$; however, when building a regression model, terms were only weakly correlated in segment 1, at lower than a $90 \%$ confidence, thus no model was built for this segment. Segment 2 (see Figure 5) was influenced by cheese aroma, cooked taste, and again preferred a low plastic aroma (all $0.50 \leq$ $\mathrm{r}<0.75)$, with all other attributes less important ( $\mathrm{r}$ $<0.50$ ). Noticeable cooked taste, sweetness, and midrange visible thickness were also desirable for segment 2 .

\section{DISCUSSION}

\section{HTST Fluid Milk with High Microbial Quality Can Maintain High Levels of Consumer Liking Even After Storage for $14 d$}

Overall, consumer liking scores showed that among non-light-exposed skim milk samples, NC samples (samples at $16 \mathrm{~d}$ postprocessing) were less liked than corresponding FR samples ( $2 \mathrm{~d}$ postprocessing). Consistent with previous reports that postpasteurization contamination of fluid milk is a major barrier to extension of HTST fluid milk shelf-life (Ralyea et al., 1998; Carey et al., 2005), 8 of the $12 \mathrm{NC}$ skim milk samples showed evidence for postpasteurization contamination based on the presence of gram-negative bacteria on crystal violet tetrazolium agar (Figure 1). The milk samples in this study that showed the highest bacterial loads after $16 \mathrm{~d}$ of refrigerated storage primarily revealed the presence of psychrotolerant gram-negative bacteria, specifically Pseudomonas sp. This is consistent with the observation that Pseudomonas sp. (as well as psychrotolerant coliform bacteria), are typically capable of growing rapidly at refrigerated temperatures, once introduced into the fluid milk supply, leading to major sensory defects 
in flavor, odor, and body (Hayes et al., 2002; Dogan and Boor, 2003). Pseudomonas has previously been identified as a predominant spoilage microorganism in fluid milk that has been contaminated postprocessing (Ralyea et al., 1998; Ranieri et al., 2009; Van Tassell et al., 2012). Hayes et al. (2002) described the aroma from different strains of Pseudomonas contaminated fluid milk as rotten hamburger/dead/rotten protein, barn/fecal/stock trailer, fruity, and other descriptors. These sensory defects are most likely attributed to the production of lipases, lecithinases and proteases, of which Pseudomonas sp. are known to produce a variety (Dogan and Boor, 2003).

Interestingly, the results of sensory analysis seemed to highlight that the shelf life of samples which lacked signs of postprocessing contamination did not deteriorate due to microbial growth, when stored correctly. In fact, the statistical model across shelf life highlighted plastic and putrid aromas, as well as visual thickness as varying with shelf life. As plastic aroma decreased with age (see Table 3), it is likely volatiles produced with light exposure dispersed to some extent with time. The origin of the variation in putrid aroma was most likely proteolysis, as indicated by $\mathrm{CN} / \mathrm{TP}$ ratios in the samples rated highest in putridity, and may have been suppressed in the light exposed samples by stronger plastic aroma. Further, both APC and PBC (representing both gram-negative and gram-positive organisms capable of growing at refrigeration) correlated with sensory ratings from panelists of putrid and sour/fermented odors, indicating that the trained sensory panel was able to sense milk of a lower microbiological quality. Results from this work imply that samples without PPC can be stored for $>14 \mathrm{~d}$ at refrigeration temperatures without notable sensory defects. Sensory defects such as sweet curdling and bitterness have been attributed to some species of sporeforming bacteria (Collins, 1981); however, further work must be performed to determine at what point sensory defects due to growth of psychrotolerant sporeformers are detectable.

\section{LED Light Exposure Results in Significantly Lower Liking of Fluid Milk}

Overall, the data suggest that consumer preference of skim and $2 \%$ milk is more profoundly influenced by exposure to light than by storage time. Although several previous reports have alluded to similar conclusions (Sattar and de Man, 1973; Bray et al., 1977; Moyssiadi et al., 2004; Gandy et al., 2008), the studies did not involve such broad general-population consumer testing paired with detailed descriptive analysis. Light-induced flavors in dairy products are in no way an unexpected or novel observation (Browne, 1899).
This study differed from earlier work in the use of more modern LED light illumination and the incorporation of a large consumer study with descriptive sensory measures. Light-activated flavors have been shown to produce robust negative consumer response (White and Bulthaus, 1982). Consumers rated FR light-exposed milks to be inferior to the FR non-light-exposed milk as well as the NC milks, both non-light-exposed and light-exposed, and often even microbiologically compromised samples. Efforts to better protect fluid milk from light exposure would safeguard both its sensory profile and its nutritional content (Singh et al., 1975). Producing milk in packaging protected from sunlight has been discussed for almost 100 yr (Hammer and Cordes, 1920), as light exposure is dependent upon wavelength of stimulus (Allen and Parks, 1979). The pattern of wavelength produced by LED lighting of course varies significantly from that of fluorescent lighting. Whereas LED lights typically are of a lower total power, they emit strongly in the blue spectrum around $460 \mathrm{~nm}$ (Heffernan et al., 2007; Narukawa et al., 2010) in a broader emission peak than fluorescents. This lies adjacent to the $450 \mathrm{~nm}$ absorption maximum of riboflavin found to be most destructive by Choe et al. (2005), and thus may be more effective in degrading riboflavin and releasing energy to the milk. A recent trend that could affect light oxidation patterns in fluid milk is the replacement, in dairy retail cases, of fluorescent lights with LED lights. These LED lights, although rapidly adopted due to lower running costs, are yet to be thoroughly characterized with respect to their effect on the degradation of photosensitizers such as riboflavin in milk (Lee and Min, 2009), a wavelength-dependent phenomenon. Although we did not compare the effects, on fluid milk, of fluorescent and LED lights, the data clearly show that LED light exposure for a relatively short period of time $(4 \mathrm{~h})$ will readily induce lightoxidized flavor, reducing consumer liking to a similar level noted in previous studies of fluorescent lighting, for example, Hoskin and Dimick (1979) noting a similar 0.5 -point drop in liking on a 9-point scale, after $6 \mathrm{~h}$ of exposure in clear containers. Interestingly, the effects of light exposure seemed to alleviate to some extent with storage, resulting in $\mathrm{NC}$ samples exposed to light $13 \mathrm{~d}$ earlier being preferred to the FR samples exposed the day before tasting.

The plant of origin was intended within the study design to serve as an indirect representation of historical quality scoring (see Carey et al., 2005; Martin et al., 2012), allowing us to evaluate consumer liking of milk with varying microbial spoilage profiles. Interestingly, consumer preference with plant of origin proved to be somewhat inconsistent. Contrasting results from microbiological analysis, it was notable that samples over 
the PMO limit of $4.31 \log \mathrm{cfu} / \mathrm{mL}$ still scored better in consumer acceptance than their FR paired samples if light-exposed (plant A light-exposed $2 \%$, plant B lightexposed $2 \%$, plant B light-exposed skim, plant $\mathrm{C}$ lightexposed skim, and plant B non-light-exposed $2 \%$ were less preferred than corresponding FR samples). It was apparent that the higher fat content of $2 \%$ milks offered some protection from the negative consumer response originating from light exposure in this study. This is in contrast to the findings of Whited et al. (2002) who found higher levels of light-induced off flavors, but less significant vitamin A degradation in the higher fat milks than in skim milk.

\section{Key Drivers of Great-Tasting Skim and 2\% Fluid Milk}

The ideal flavor of milk is not a static concept, but varies with time, and with ongoing trends (Thomas, 1981). Maximizing the consumer acceptance of dairy products remains a clear and actionable step toward arresting the decline in the sales of fluid milk. Cow milk is still robustly preferred in blind tasting over various nondairy milk products cannibalizing the fluid milk market (Palacios et al., 2009). Based on combining analysis of sensory and consumer data, it is possible to predict an optimal product for consumers. The sensory profiles of a set of idealized target products are presented in Table 4. Predicted intensity ratings for the target products are based on results of preference mapping (MacFie and Thomson, 1988; Meilgaard et al., 2016). Attributes are grouped by their key sensory dimension (e.g., texture, appearance, aroma, taste). The results of segmentation analysis are in agreement with the target levels for most attributes; however, when some disagreement is evident, a compromise is noted, along with acceptable ranges. Dual-segment targets are set to maximize overall liking within both segments, while staying inside the sensory space spanned by the products in the test. For example, in skim milk samples, consumers will tolerate a whiteness between 3.4 and 4.3 on a 10-point scale; thus, a target of 3.9 is set as an acceptable compromise to consumers. Due to a tolerance for a low level of putrid aroma in one consumer segment (1.5 vs. sub-threshold in alternated segment), across both segments, $2 \%$ milk was not penalized in consumer liking despite suffering from a low level of putrid aroma.

This work highlights the importance of the protection of fluid milk from exposure to light. While this has been noted for many years, with many interventions

Table 4. Attribute targets and ranges for compromise between consumer segments for skim and $2 \%$ milks; scale is numbered from 0 to 10 , with 0 representing not detected, and 10 representing very strong for flavor and aromas, or very white for whiteness ${ }^{1}$

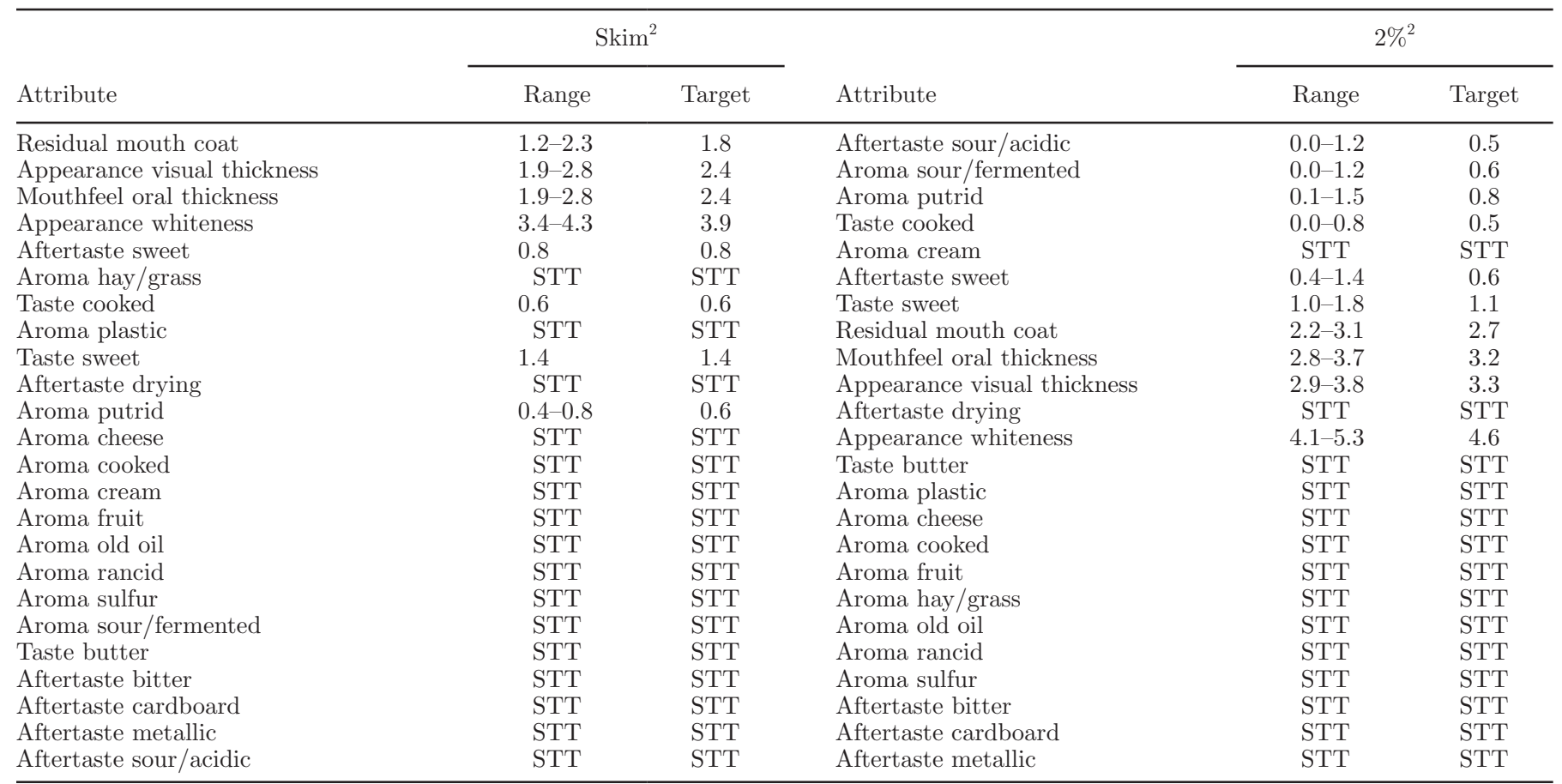

${ }^{1}$ Thickness was rated from very thin to very thick. Model predicts consumer acceptance based on existing product factor scores, from both total respondent base and from consumer segments. Target products were modeled from combined factor scores within the sensory space of products tested with highest predicted liking.

${ }^{2} \mathrm{STT}=$ sub-threshold target $(<0.5$ points $)$. 
to control light existing (e.g., light-blocking packaging, Mestdagh et al., 2005), few are employed in the industry as standard. In the future, to ensure delivery of the highest quality milk to consumers, protection from light represents an actionable source of product improvement, one that could be of great benefit to the continued success of the dairy industry.

\section{ACKNOWLEDGMENTS}

This publication was made possible by the research funding provided by Dairy Management Inc. (Rosemont, IL) and the Midwest Dairy Association (St. Paul, $\mathrm{MN}$ ), and administered by National Dairy Council (Rosemont, IL). Consumer testing was administered by Peryam and Kroll (Chicago, IL), with additional analysis by DMI, Peryam and Kroll, and Carr Consulting (Wilmette, IL). Peryam and Kroll and Carr Consulting were compensated for their services.

\section{REFERENCES}

Adams, M. C., and D. M. Barbano. 2013. Serum protein removal from skim milk with a 3 -stage, $3 \times$ ceramic Isoflux membrane process at $50^{\circ}$ C. J. Dairy Sci. 96:2020-2034.

Allen, C., and O. W. Parks. 1979. Photodegradation of riboflavin in milks exposed to fluorescent light. J. Dairy Sci. 62:1377-1379.

Allen, J. C., and G. Joseph. 1985. Deterioration of pasteurized milk on storage. J. Dairy Res. 52:469-487.

Aurand, L. W., N. H. Boone, and G. G. Giddings. 1977. Superoxide and singlet oxygen in milk lipid peroxidation. J. Dairy Sci. 60:363-369.

Barbano, D. M., J. L. Clark, and C. E. Dunham. 1988. Comparison of the Babcock and ether extraction methods for determination of fat content of milk: Collaborative study. J. Assoc. Off. Anal. Chem. 71:898-914.

Barbano, D. M., J. M. Lynch, and J. R. Fleming. 1991. Direct and indirect determination of true protein content of milk by Kjeldahl analysis: Collaborative study. J. Assoc. Off. Anal. Chem. 74:281288.

Barbano, D. M., Y. Ma, and M. V. Santos. 2006. Influence of raw milk quality on fluid milk shelf life. J. Dairy Sci. 89(E. Suppl.):E15E19.

Barcia, M. L., B. Sanz, P. Garcia-Collia, and J. A. Ordonez. 1989. Activity and thermostability of the extracellular lipases and proteinases from pseudomonads isolated from raw milk. Milchwissenschaft 44:547-550.

Bradley, R. L. Jr. 1980. Effect of light on alteration of nutritional value and flavor of milk: A review. J. Food Prot. 43:314-320.

Bray, S. L., A. H. Duthie, and R. P. Rogers. 1977. Consumers can detect light-induced flavor in milk. J. Food Prot. 40:586-587.

Browne, C. A. 1899. A contribution to the chemistry of butter-fat. J. Am. Chem. Soc. 21:975-994.

Cardoso, D. R., S. H. Libardi, and L. H. Skibsted. 2012. Riboflavin as a photosensitizer. Effects on human health and food quality. Food Funct. 3:487-502.

Carey, N. R., S. C. Murphy, R. N. Zadoks, and K. J. Boor. 2005. Shelf lives of pasteurized fluid milk products in New York State: A ten year study. Food Prot. Trends 25:102-113.

Chapman, K. W., H. T. Lawless, and K. J. Boor. 2001. Quantitative descriptive analysis and principal component analysis for sensory characterization of ultrapasteurized milk. J. Dairy Sci. 84:12-20.
Chapman, K. W., L. J. Whited, and K. J. Boor. 2002. Sensory threshold of light-oxidized flavor defects in milk. J. Food Sci. 67:27702773.

Choe, E., R. Huang, and D. B. Min. 2005. Chemical reactions and stability of riboflavin in foods. J. Food Sci. 70:R28-R36.

Choe, E., and D. B. Min. 2005. Chemistry and reactions of reactive oxygen species in foods. J. Food Sci. 70:R142-R159.

Clark, J. L., D. M. Barbano, and C. E. Dunham. 1989. Comparison of two methods for determining total solids content of raw milk: Collaborative study. J. Assoc. Off. Anal. Chem. 72:712-718.

Collins, E. B. 1981. Heat resistant psychrotrophic microorganisms. J. Dairy Sci. 64:157-160.

De Jonghe, V., A. Coorevits, K. Van Hoorde, W. Messens, A. Van Landschoot, P. De Vos, and M. Heyndrickx. 2011. Influence of storage conditions on the growth of Pseudomonas species in refrigerated raw milk. Appl. Environ. Microbiol. 77:460-470.

Dogan, B., and K. J. Boor. 2003. Genetic diversity and spoilage potentials among Pseudomonas spp. isolated from fluid milk products and dairy processing plants. Appl. Environ. Microbiol. 69:130-138.

Findlay, C. J., J. C. Castura, and I. Lesschaeve. 2007. Feedback calibration: A training method for descriptive panels. Food Qual. Prefer. 18:321-328.

Fisher, J., D. Mitchell, H. Smiciklas-Wright, and L. Birch. 2001. Maternal Milk Consumption predicts the tradeoff between milk and soft drinks in young girls' diets. J. Nutr. 131:246-250.

Fromm, H. I., and K. J. Boor. 2004. Characterization of pasteurized fluid milk shelf-life attributes. J. Food Sci. 69:M207-M214.

Gandy, A. L., M. W. Schilling, P. C. Coggins, C. H. White, Y. Yoon, and V. V. Kamadia. 2008. The effect of pasteurization temperature on consumer acceptability, sensory characteristics, volatile compound composition, and shelf-life of fluid milk. J. Dairy Sci. 91:1769-1777.

Hammer, B. W., and W. A. Cordes. 1920. A study of brown glass milk bottles with special reference to their use in preventing abnormal flavors due to light. Iowa Agric. Expt. Sta. Res. Bull. (Sun Chiwawitthaya Thang Thale Phuket) 64:246.

Hankin, L. L., W. F. Dillman, and G. R. Stephens. 1977. Keeping quality of pasteurized milk for retail sail related to code date, storage temperature and microbial counts. J. Food Prot. 40:843-853.

Hayes, W., C. H. White, and M. A. Drake. 2002. Sensory aroma characteristics of milk spoilage by Pseudomonas species. J. Food Sci. $67: 448-454$.

Heffernan, W. J. B., L. P. Frater, and N. R. Watson. 2007. LED Replacement for Fluorescent Tube Lighting. Power Engineering Conference, AUPEC 2007, Australasian Universities, Perth, WA. p 4.

Hooi, R., D. M. Barbano, R. L. Bradley, D. Budde, M. Bulthaus, M. Chettiar, J. Lynch, and R. Reddy. 2004. Chemical and physical methods. Pages 363-536 in Standard Methods for the Examination of Dairy Products. 17th ed. H. M. Wehr and J. F. Frank, ed. Am. Public Health Assoc., Washington, DC.

Hoskin, J. C., and P. S. Dimick. 1979. Evaluation of fluorescent light on flavor and riboflavin content of milk held in gallon returnable containers. J. Food Prot. 42:105-109.

IDFA. 2013. Fluid milk sales and consumption. Page 65 in Dairy Facts. International Dairy Foods Association, Washington, DC.

Ivy, R. A., M. L. Ranieri, N. H. Martin, H. C. den Bakker, B. M. Xavier, M. Wiedmann, and K. J. Boor. 2012. Identification and characterization of psychrotolerant sporeformers associated with fluid milk production and processing. Appl. Environ. Microbiol. 78:1853-1864.

Jung, M. Y., S. H. Yoon, H. O. Lee, and D. B. Min. 1998. Singlet oxygen and ascorbic acid effects on dimethyl disulfide and off-flavor in skim milk exposed to light. J. Food Sci. 63:408-412.

Kaylegian, K. E., G. E. Houghton, J. M. Lynch, J. R. Fleming, and D. M. Barbano. 2006a. Calibration of infrared milk analyzers: Modified milk vs. producer milk. J. Dairy Sci. 89:2817-2832.

Kaylegian, K. E., J. M. Lynch, J. R. Fleming, and D. M. Barbano. 2009. Influence of fatty acid chain length and unsaturation on midinfrared milk analysis. J. Dairy Sci. 92:2485-2501.

Kaylegian, K. E., J. M. Lynch, G. E. Houghton, J. R. Fleming, and D. M. Barbano. 2006b. Modified versus producer milk calibra- 
tion: Mid-infrared analyzer performance validation. J. Dairy Sci. 89:2833-2845.

Kosa, K. M., S. C. Cates, S. Karns, S. L. Godwin, and D. Chambers. 2007. Consumer home refrigeration practices: results of a web based survey. J. Food Prot. 70:1640-1649.

Laird, D. T., A. Gambrel-Lenarz, F. M. Scher, T. E. Graham, and R. Reddy. 2004. Microbiological count methods. Pages 153-186 in Standard Methods for the Examination of Dairy Products. 17th ed. H. M. Wehr and J. F. Frank, ed. Am. Public Health Assoc., Washington, DC.

Lee, J. H., and D. B. Min. 2009. Changes of headspace volatiles in milk with riboflavin photosensitization. J. Food Sci. 74:C563-C568.

Lee, K. H., M. Y. Jung, and S. Y. Kim. 1998. Effects of ascorbic acid on the light-induced riboflavin degradation and color changes in milks. J. Agric. Food Chem. 46:407-410.

Lynch, J. M., D. M. Barbano, and J. R. Fleming. 2007. Determination of lactose content of fluid milk by spectrophotometric enzymatic analysis using weight additions and path length adjustment: Collaborative study. J. AOAC Int. 90:196-216.

MacFie, H. J. H., and D. M. H. Thomson. 1988. Preference mapping and multidimensional scaling. Pages 381-407 in Sensory Analysis of Foods. J. R. Piggott, ed. Elsevier Science Publishers, Barking, UK.

Martin, N. H., N. R. Carey, S. C. Murphy, M. Wiedmann, and K. J. Boor. 2012. A decade of improvement: New York State fluid milk quality. J. Dairy Sci. 95:7384-7390.

Masiello, S. N., N. H. Martin, R. D. Watters, D. M. Galton, Y. H. Schukken, M. Wiedmann, and K. J. Boor. 2014. Identification of dairy farm management practices associated with the presence of psychrotolerant sporeformers in bulk tank milk. J. Dairy Sci. 97:4083-4096.

Meilgaard, M. C., G. V. Civille, and B. T. Carr. 2016. Sensory Evaluation Techniques, 5th ed. CRC Press, Taylor and Francis Group, Boca Raton, FL.

Mestdagh, F., B. De Meulenaer, J. De Clippeleer, F. Devlieghere, and A. Huyghebaert. 2005. Protective influence of several packaging materials on light oxidation of milk. J. Dairy Sci. 88:499-510.

Moyssiadi, T., A. Badeka, E. Kondyli, T. Vakirtzi, I. Savvaidis, and M. G. Kontominas. 2004. Effect of light transmittance and oxygen permeability of various packaging materials on keeping quality of low fat pasteurized milk: chemical and sensorial aspects. Int. Dairy J. 14:429-436.

Narukawa, Y., M. Ichikawa, D. Sanga, M. Sano, and T. Mukai. 2010 White light emitting diodes with super-high luminous efficacy. J. Phys. D Appl. Phys. 43:1-6.

Palacios, O. M., J. Badran, M. Drake, M. Reisner, and H. R. Moskowitz. 2009. Consumer acceptance of cow's milk versus soy beverages:
Impact of ethnicity, lactose tolerance and sensory preference segmentation. J. Sens. Stud. 24:731-748.

Qannari, E. M., E. Vigneau, P. Luscan, A. C. Lefebvre, and F. Vey. 1997. Clustering of variables, application in consumer and sensory studies. Food Qual. Prefer. 8:423-428.

Ralyea, R. D., M. Wiedmann, and K. J. Boor. 1998. Bacterial tracking in a dairy production system using phenotypic and ribotyping methods. J. Food Prot. 61:1336-1340.

Ranieri, M. L., J. R. Huck, M. Sonnen, D. M. Barbano, and K. J. Boor. 2009. High temperature, short time pasteurization temperatures inversely affect bacterial numbers during refrigerated storage of pasteurized fluid milk. J. Dairy Sci. 92:4823-4832.

Sattar, A., and J. M. de Man. 1973. Effect of packaging material on light induced quality deterioration of milk. Can. Inst. Food Sci. Technol. J. 6:170-174.

Schröder, M. J. 1984. Origins and levels of post pasteurization contamination of milk in the dairy and their effects on keeping quality J. Dairy Res. 51:59-67.

Simões, M., L. C. Simões, and M. J. Vieira. 2010. A review of current and emergent biofilm control strategies. LWT Food Sci. Technol. 43:573-583.

Singh, R. P., D. R. Helderman, and J. R. Kirk. 1975. Kinetic analysis of light-induced riboflavin loss in whole milk. J. Food Sci. 40:164167.

Stewart, H., D. Dong, and A. Carlson. 2012. Is generational change contributing to the decline in fluid milk consumption? J. Agric Res. Econ. 37:435-454.

Stone, H., and J. L. Sidel. 1998. Quantitative descriptive analysis: Developments, applications and the future. Food Technol. (USA) $52: 48-52$.

Thomas, E. L. 1981. Trends in milk flavors. J. Dairy Sci. 64:1023-1027.

Van Tassell, J. A., N. H. Martin, S. C. Murphy, M. Wiedmann, K. J. Boor, and R. A. Ivy. 2012. Evaluation of various selective media for the detection of Pseudomonas species in pasteurized milk. J. Dairy Sci. 95:1568-1574.

White, C. H., and M. Bulthaus. 1982. Light activated flavor in milk J. Dairy Sci. 65:489-494.

Whited, L. J., B. H. Hammond, K. W. Chapman, and K. J. Boor 2002. Vitamin A degradation and light-oxidized flavor defects in milk. J. Dairy Sci. 85:351-354.

Wold, J. P. A. Veberg, A. Nilsen, V. Iani, P. Juzenas, and J. Moan. 2005. The role of naturally occurring chlorophyll and porphyrins in light-induced oxidation of dairy products. A study based on fluorescence spectroscopy and sensory analysis. Int. Dairy J. $15: 343-353$. 